\title{
POSTURAS DOCENTES E FORMAÇÃO UNIVERSITÁRIA DE PROFESSORES DO ENSINO FUNDAMENTAL
}

\author{
CLAUDIA DAVIS \\ Departamento de Pesquisas Educacionais da Fundação Carlos Chagas \\ e Programa de Estudos Pós-Graduados em Psicologia da \\ Educação da Pontifícia Universidade Católica de São Paulo \\ cdavis@fcc.org.br \\ YARA LÚCIA ESPOSITO \\ Departamento de Pesquisas Educacionais da Fundação Carlos Chagas \\ yesposito@fcc.org.br \\ MARINA M. R. NUNES \\ Departamento de Pesquisas Educacionais da Fundação Carlos Chagas e \\ Colégio Santa Cruz \\ mnunes@fcc.org.br

\section{CESAR A. A. NUNES} \\ Escola do Futuro e Núcleo de Tecnologia da Informação e \\ Comunicação Aplicadas à Educação da Universidade de São Paulo \\ cnunes@futuro.usp.br

\section{MIRIAM BIZZOCCHI} \\ Departamento de Pesquisas Educacionais da Fundação Carlos Chagas \\ mbizzocchi@fcc.org.br
}

\section{RESUMO}

O objetivo desse trabalho foi avaliar se a participação de professores de redes municipais do Estado de São Paulo em um programa de licenciatura em nível superior, oferecido por duas renomadas universidades paulistas, ocasionava alteração nas posturas docentes dos alunosprofessores. Os dados - respostas de 1.272 participantes a 17 simulações de situações problemas apresentadas no início e no final do programa - foram analisadas por meio de procedimentos estatísticos. Os resultados mostraram que 30\% dos alunos-professores sofreram modificações de perfil nas posturas estudadas no sentido esperado. Isso parece indicar que os participantes apresentaram, ao final do Programa, maior tendência para dominar e planejar situações didáticas que envolviam os conteúdos básicos das áreas de conhecimento; re- 
conhecer e empregar adequadamente os recursos e tecnologias disponíveis no processo de ensino-aprendizagem; e valer-se da teoria para orientar a prática docente e a avaliação AVALIAÇÃO DO PROGRAMA - PERFIL PROFISSIONAL DO PROFESSOR - PRÁTICA DE ENSINO - PSICOLOGIA DA EDUCAÇÃO

\section{ABSTRACT}

PEDAGOGICAL POSTURES AND UNDERGRADUATE STUDIES OF TEACHER LINKED TO FUNDAMENTAL SCHOOL. The goal of this study was to evaluate if participation in a university level Education program (devoted to form elementary teachers) caused an impact on the postures of pupils that were already teaching at counties'schools. The data - answers given by 1272 participants linked to two highly known universities in the state of São Paulo (Brazil) to 17 simulations that encompassed initial and final evaluation - were analyzed by statistical procedures. The results showed that $30 \%$ of the subjects had their profiles altered in the expected direction in the focused postures, implying that at the end of the Program they demonstrated a tendency to dominate and plan didactic situations involving basic contents of knowledge areas; recognize and employ adequately the resources and the technologies available to the teaching and learning process; and to use theory to orient teaching and evaluation.

PROGRAMME EVALUATION - TEACHER PROFILE - EDUCATIONAL PRACTICE EDUCATIONAL PSYCHOLOGY

Este estudo teve como objetivo discutir as mudanças encontradas nas posturas docentes de professores de ensino fundamental, do início para o final de um programa de licenciatura para a formação de professores, em nível superior. $\bigcirc$ trabalho está estruturado em quatro partes distintas. Na primeira, são apresentados o contexto no qual o referido programa foi criado, bem como seu público-alvo, principais objetivos, currículo e métodos. Na segunda parte, descreve-se a pesquisa, seus principais objetivos, o conceito de "postura docente" adotado a partir da literatura e o instrumento utilizado. Passa-se, então, para a terceira parte, que relata os resultados. Finalmente, na quarta, são feitas algumas considerações sobre a mudança de postura em programas de capacitação continuada.

\section{O PRO GRAMA DE EDUCAÇÃO CONTINUADA DO ESTADO DE SÃO PAULO}

Ao final dos anos 90, o governo do Estado de São Paulo decidiu formar em nível superior os professores que, contando apenas com habilitação em nível 
médio, eram vinculados à rede estadual de ensino. Para tanto, foi elaborado o Programa de Educação Continuada em Formação Universitária, denominado PEC-Formação Universitária, que se realizou com a parceria de três renomadas universidades paulistas. Encerrada a etapa de formação dos professores na rede estadual, o programa foi oferecido, com alguns ajustes - participaram dele apenas duas das três universidades que o implementaram originalmente -, a municípios que tinham interesse de propiciar curso superior a seus quadros. Esse programa foi intitulado, para se diferenciar do anterior, PEC-Municípios.

\section{Principais características do PEC -Municípios}

programa foi desenvolvido por meio de ambientes de aprendizagem distribuídos ao longo do estado e localizados em vários Centros de Formação e Aperfeiçoamento do Magistério - Cefams. A carga horária, de acordo com os termos da lei, foi de 3.100 horas no total, assim distribuída:

- 1.600 horas de aulas;

- 400 horas de atividades complementares que deveriam resultar em trabalhos individuais, relacionando teorias e práticas escolares no ensino;

- 300 a 800 horas de prática de ensino, variando segundo avaliação do aluno em sua experiência prévia na docência.

Nos procedimentos de ensino, foram adotadas várias estratégias:

- Videoconferências: proferidas por professores das universidades (mestres ou doutores), para fornecer o embasamento teórico-conceitual a cada tema em estudo. Alunos de diferentes salas podiam comunicar-se com o docente ao vivo, bem como com os colegas das demais salas, criando uma rede rica de interações.

- Teleconferências: transmitidas de um único ponto e assistidas por todos os alunos, permitiam interação com os palestrantes via fax, internet ou telefone.

- Trabalho monitorado: aprofundava e enriquecia os tópicos estudados nas aulas por videoconferência ou teleconferência e se voltavam, mais especificamente, para as tarefas em sala de aula. 
- Vivências educadoras: buscavam assegurar a articulação de referências teórico-conceituais ao dia-a-dia do professor.

- Oficinas culturais: pretendiam ampliar o universo cultural dos alunosprofessores.

\section{Currículo}

A proposta pedagógica envolvia um módulo introdutório, voltado para a capacitação dos alunos-professores em informática, e quatro outros, dedicados à formação específica, os quais, integrados a vivências práticas, abordavam, respectivamente, os seguintes tópicos:

- dimensão experiencial, reflexiva e ética do trabalho docente;

- formação para a docência escolar, incluindo o cenário político-pedagógico atual, conteúdos e didáticas das áreas curriculares;

- currículo, envolvendo espaço e tempo de decisão coletiva;

- escola como um elo na rede da sociedade do conhecimento.

A organização curricular deveria garantir a ampliação e o aprofundamento dos conhecimentos sobre os conteúdos de ensino, a construção de competências e o uso de tecnologias avançadas em comunicação e informação.

\section{A PESQ UISA E SEUS OBJETIVOS}

A equipe gestora do projeto', que atuava em nome da Fundação para o Desenvolvimento da Educação - FDE -, solicitou um estudo que verificasse se esse programa de formação, em função de seu caráter inovador e do uso de mídias interativas, tinha propiciado alterações nas posturas dos professores que o freqüentaram. Duas outras questões, decorrentes da primeira, deveriam também ser respondidas: ao se encontrar alterações nas posturas docentes, elas evidenciariam um efeito positivo do Programa PEC-Municípios? Como os resultados alcançados (a observação ou não de mudanças nas posturas docentes) poderiam ser explicados?

I. A equipe gestora era constituída por professores doutores em educação, por professores e por técnicos em informática, todos ligados à Fundação Vanzolini. 


\section{Referencial teórico}

Foi analisada a literatura disponível para definir claramente o que se entendia por "posturas". Baseou-se na seguinte definição: "posturas são tendências ou disposições adquiridas e relativamente duradouras, que levam as pessoas a avaliar, de um determinado modo, um objeto, indivíduo, acontecimento ou situação e a atuar de acordo com tal avaliação" (Coll et al., 1992). O caráter das posturas está, portanto, em articular ação, compreensão e disposição, para explicar e nortear os modos de ser do sujeito. Dessa forma, elas são constituídas na atividade e para ela se dirigem. De acordo com nossa experiência (Nunes, Nunes, Davis, 2003), posturas expressam uma forma de organizar, esclarecer e articular as dimensões centrais da atividade: as informações advindas do mundo no qual se vive e se atua (dimensão cognitiva), sua base volitiva (dimensão afetiva) e as ações envolvidas (dimensão motora). Quando surgem defasagens grandes entre o que se faz, pensa e sente, cria-se um estado de insatisfação que pode levar a uma eventual mudança na forma pela qual se executa uma certa atividade como, por exemplo, a docente. Assim, quando a prática profissional já não pode ser mais compreendida, explicada ou justificada com base nas idéias que se tem sobre ela, ou nos sentimentos que ela ou suas ações despertam, as posturas tendem a se enfraquecer e a exigir modificações nas ações, visando a reconciliá-las com os aspectos cognitivos e afetivos que as legitimam.

Posturas tendem, assim, a imprimir certa consistência, coerência e estabilidade à atividade, modificando-a sempre que se experimenta um estado de inconsistência entre o que se faz, pensa e sente. Nessas situações, um outro estado é buscado, no qual prevaleça maior coerência entre o pensar, o sentir e o agir, em que seja possível reconciliar as novas informações com as experiências anteriores, base sobre a qual as posturas se assentam. Pode-se dizer, portanto, que mudanças de posturas tendem a ocorrer mais facilmente quando o indivíduo experimenta uma discrepância entre uma dada ação e novas informações (e sentimentos) acerca da realidade ou entre suas ações e aquelas de outras pessoas consideradas significativas.

Um outro fator de peso a ser considerado na modificação de posturas está no que Eiser (1989, p. 32) chama de "expressão externa" ou "referência pública": a atividade propicia sempre uma maneira de identificar as formas de 
pensar e de sentir que estão nela imbricadas. Coll et al. ( 1992) salientam que é justamente pelo caráter público das ações, que a noção de consistência (ou de coerência) adquire uma importância nodal no processo de mudança de postura. Para ele, a referência pública permite às posturas serem definidas como consistentes, estáveis ou típicas, a depender de quão relacionadas estejam ao que se diz, sente e faz. Pode-se, no entanto, não ser coerente na mesma medida e mesmo em situações semelhantes, sem que as ações - e posturas - sejam necessariamente percebidas como inconsistentes. Outros fatores como, por exemplo, o desejo de ser acolhido e aceito por outros significativos, concorrem com a busca de consistência. Assim, encontra-se uma situação bastante contraditória: se novas informações foram apropriadas pelo sujeito, elas tendem a gerar nele inconsistências e também a busca por maior coerência. Mas esse movimento no sentido de ultrapassar as inconsistências, por implicar abandonar o conhecido e se lançar no novo, gera resistências, cuja meta é justamente fugir dos transtornos que a própria mudança acarreta.

Por envolver tantos e variados aspectos, mudanças de posturas muito raramente ocorrer em curto prazo. A literatura consultada aponta para esse fato: o processo de mudança é lento, de sorte que rápidas e consistentes alterações nelas não devem ser esperadas. Posturas parecem mesmo interferir no processo de mudança da atividade ao gerar a busca por coerência e estabilidade, mas são cautelosas em seu caminhar. Isso não significa, entretanto, que não se possa tentar transformar, deliberada e intencionalmente, mediante formação, posturas consideradas indesejáveis, esperando que elas retornem à atividade, modificando-a. De fato, a formação continuada, mais do que a inicial, parece propiciar exatamente isso: novas idéias que, ao coexistirem com velhas práticas, acabam por gerar o mal-estar da inconsistência e a tentativa de evitála. Essa modalidade de ensino cria, portanto, condições favoráveis para avaliar posturas, verificando se elas foram reafirmadas ou transformadas, e se incidem, por sua vez, sobre determinadas ações.

Alterar posturas para que elas se encaminhem na direção dos modos de agir, pensar e sentir socialmente valorizados exige: modificações cognitivas, por meio do fornecimento de novas informações que tenham um maior e melhor potencial explicativo das ações; estabelecimento de relações afetivas e emocionais fortes nas circunstâncias em que a mudança ocorre; capacidade de generalização da postura adotada, por abarcar um leque grande de experiências. 
Assim, muito embora posturas sejam efetivamente duradouras, tendendo a se prolongar no tempo, elas são suficientemente permeáveis para sofrer alterações. Com base nos postulados de Atherton (1999), definiram-se alguns momentos do processo de mudança: o da desestabilização, em que as formas de ser, pensar e agir não se coadunam mais e as inconsistências levam à avaliação de que são inadequadas e/ou indesejáveis; o dos ensaios de mudança, em que se criam resistências ao novo e as ações modificam-se devagar; e, finalmente, o de reorientação, quando as barreiras são vencidas, permitindo de novo a articulação das três dimensões da atividade.

Considerou-se, assim, que posturas emergem da atividade dos sujeitos e a ela se dirigem, configurando-se como uma forma relativamente duradoura de compreender algo - ou alguém ou alguma coisa - e de atuar de acordo com tal compreensão, para manter a coerência entre os modos de fazer, sentir e pensar. Com base nessa definição, delineou-se uma avaliação que permitisse aquilatar se a freqüência ao PEC-Municípios tinha ensejado, nos alunos-professores, o aparecimento de novas posturas acerca do processo de ensinoaprendizagem. Partiu-se de três pressupostos sobre as posturas: o de que elas não são passíveis de ser diretamente observadas, ainda que possam ser inferidas a partir de determinadas ações ${ }^{2}$; o de que elas não podem ser avaliadas em um único momento, nem em um único contexto; o de que elas são mais bem avaliadas por meio de situações-problema que permitam considerar várias possibilidades de atuação.

\section{0 instrumento}

Tomando como base o referencial teórico adotado, a experiência prévia dos autores e as orientações teórico-metodológicas propostas pelo PECMunicípios, foi elaborado um instrumento que envolvia 17 situações-problema, configuradas como animações interativas, que simulavam tarefas inerentes

2. Segundo Mislevy (1996), as informações disponíveis são, de modo geral, incompletas e não conclusivas: raciocina-se sempre na presença de incertezas. Quando as informações, a despeito disso, são tidas como relevantes, ou seja: quando colaboram para o teste de hipóteses acerca de um determinado evento, fenômeno ou situação, pensa-se e se procede com base nelas, pelo uso de inferências. Infere-se, portanto, quando se parte do que se faz, conhece ou observa, para chegar a conclusões, explanações e predições. 
ao dia-a-dia escolar: planejamento, objetivos a serem atingidos no trabalho com os alunos, modalidades de avaliação etc. Cada tarefa exigia que decisões fossem tomadas pelos participantes. As tarefas, por sua vez, permitiam identificar se havia afinidade entre os procedimentos selecionados pelos alunos-professores e aqueles propostos pelo programa em estudo.

Três conjuntos de situações-problema foram criados com vistas a identificar como os alunos-professores se posicionavam diante de situações didáticas. Neles eram ressaltados: o domínio e o planejamento de conteúdos básicos das áreas de conhecimento tratadas no programa; o reconhecimento e emprego adequado dos recursos e das tecnologias disponíveis no processo de ensinoaprendizagem; o emprego da teoria para orientar a prática docente nos processos de ensinar, aprender e avaliar. Como as simulações apresentavam um caráter transversal, elas permitiriam identificar a posição assumida pelo aluno-professor em mais de um desses conjuntos. Na medida em que todos envolviam a análise e avaliação das situações-problema (compreensão) e a tomada de posição diante das diferentes possibilidades de ação oferecidas, os conjuntos foram a priori denominados respectivamente de postura I, postura II e postura III.

Definiu-se, ainda, que cada postura envolveria três situações claramente delimitadas, a depender do grau de domínio sobre a proposta didática almejada pelo programa e sobre os procedimentos de ensino dela decorrentes: se eles já eram conhecidos e dominados; se eram apenas parcialmente apreendidos e, portanto, também parcialmente dominados; se não eram nem conhecidos nem dominados. Com base nisso, foi possível classificar cada uma das respostas dadas às simulações ${ }^{3}$, encontrando-se três perfis distintos associados a cada postura. Dessa forma, as posturas e seus perfis, aferidos pelo grau de domínio em relação à proposta pedagógica do programa foram descritos como segue:

- Postura l: domínio e planejamento de conteúdos básicos das áreas de conhecimento tratadas no programa. Integravam esse conjunto sete simulações ligadas às disciplinas de Língua Portuguesa, História, Matemática e Ciências. Buscava-se, de uma maneira geral, verificar se os

3. Os autores atuaram como juízes, cada um deles classificando parte das respostas dos alunosprofessores. Sempre que divergências foram observadas, fez-se uso de um procedimento de triangulação para eliminá-las. 
alunos-professores valorizavam: o trabalho com diferentes gêneros de discurso, salientando sua estrutura; a manipulação de materiais em situações experimentais, bem como a reflexão científica acerca dos dados coletados; o uso de novas tecnologias no ensino, sempre que elas se mostrassem pertinentes; o conhecimento prévio, o diálogo e a expressão dos alunos, ao planejar as aulas; e a forma proposta pelo programa acerca de como trabalhar os conteúdos de História e Geografia.

- Perfil A: o aluno-professor demonstra articular bem teoria e prática, em consonância com o esperado no programa. Seriam aqui classificados aqueles participantes que elegeram, na maioria das vezes, respostas que indicavam tanto domínio dos conteúdos básicos das áreas de conhecimento como planejamento conseqüente. Típico desse grupo é, por exemplo, o seguinte perfil:

O professor prioriza o experimento científico, valoriza a manipulação dos materiais por parte das crianças e aproveita a situação para estimular a reflexão do grupo sobre seus resultados.

- Perfil B: o aluno-professor parece já ter entrado em contato com a linha pedagógica adotada pelo Programa, ainda que aparentemente não a empregue de forma sistemática em sua prática docente. Incluiriam-se aqui os participantes com respostas que demonstrassem, na maioria das simulações, reconhecimento de quais eram as condutas mais adequadas, sem conseguir, no entanto, adotá-las nas tomadas de decisão subseqüentes. $\bigcirc$ exemplo ilustra bem o perfil desses sujeitos:

O professor prioriza o experimento científico, manipulando ele mesmo os materiais ao invés de deixar isso para as crianças, além de dar ênfase ao registro de dados sem estimular, antes, reflexão sobre o que significam.

- Perfil C: as respostas dos integrantes desse grupo indicavam desconhecimento dos conteúdos básicos divulgados no programa. Ficariam aqui incluídos os alunos-professores que selecionaram, de maneira sistemática, respostas que revelavam enfoque e planejamento muito distantes dos pretendidos, como nos exemplos: 
professor não prioriza o experimento científico, nem valoriza a manipulação dos materiais por parte das crianças, deixando ainda de promover a reflexão do grupo sobre seus resultados;

O professor fornece respostas contraditórias, que não permitem nenhum tipo de análise sobre como se posiciona em relação ao experimento científico (reposta inconsistente).

- Postura //: reconhecimento e emprego adequado dos recursos e tecnologias disponíveis no processo de ensino-aprendizagem. Faziam parte dela nove simulações, todas vinculadas a modalidades de aprendizagem significativa. Buscava-se verificar, portanto, se o professor reconhecia: a pertinência de fazer uso de diferentes instrumentos para desenvolver o raciocínio dos alunos das séries iniciais; os aspectos considerados relevantes para promover uma aprendizagem significativa; a necessidade de assegurar um clima e/ou um ambiente agradável de aprendizagem; o valor da atitude investigativa para a formação intelectual dos alunos.

- Perfil A: envolve respostas favoráveis à aprendizagem significativa, revelando compreensão, organização e uso interessante de procedimentos pedagógicos, bem como de recursos didáticos e tecnológicos. Nesse grupo seriam classificados os alunos-professores que escolhessem, na maioria das simulações, alternativas que fossem ao encontro das orientações metodológicas e didáticas apregoadas no decorrer do programa, tal como:

professor demonstra saber fazer uso adequado da tecnologia, indicando, ao analisar uma tarefa, que percebe plenamente sua pertinência para o desenvolvimento do raciocínio de alunos das séries iniciais.

- Perfil B: abarca repostas favoráveis à aprendizagem com significado, tendo em vista que o professor organiza e emprega, de forma motivadora, procedimentos pedagógicos e recursos didáticos e tecnológicos. Não obstante, tais respostas não demonstram nem clareza acerca dos objetivos perseguidos, nem de seu alcance. Poderiam ser classificados aqui os participantes que davam respostas que permitiam inferir que reconheciam o que era deles esperado, sem sa- 
ber ao certo, no entanto, quais eram as melhores formas de explorar essas possibilidades. Define bem esse perfil o exemplo:

O professor demonstra saber fazer uso adequado da tecnologia, mas analisa a atividade proposta por meio de justificativas que indicam falta de clareza quanto aos seus objetivos.

- Perfil C: implica atuação tradicional (na qual se mantêm procedimentos de ensino-aprendizagem que dificilmente auxiliam os alunos a alcançarem aprendizagens significativas) e/ou inconsistente (que não permite se reconheça, organize ou implemente, de forma interessante, os procedimentos pedagógicos e os recursos didáticos e tecnológicos junto ao corpo discente). Nesse grupo, seriam incluídos os alunos-professores, para os quais: a ênfase educacional estivesse em permitir a aquisição de uma fala correta como pré-requisito para a escrita; as informações anteriores acerca do rendimento dos alunos fossem utilizadas apenas e tão-somente para identificar os menos experientes em termos de aprendizagem e colocá-los sentados à frente; as regras que regiam a classe deveriam ser afixadas em um mural, sem discussão prévia com os alunos. Os exemplos que se seguem são ilustrativos desse perfil:

O professor acredita que o uso da tecnologia pode inibir o desenvolvimento do raciocínio do aluno, mostrando-se desatualizado quanto às suas possibilidades de emprego;

O professor acredita nas possibilidades da tecnologia, mas aponta que ela inibe o raciocínio do aluno (resposta inconsistente).

- Postura III: emprego da teoria para orientar a prática docente, nos processos de ensinar, aprender e avaliar. Pertenciam a esse grupo oito simulações, cujo objetivo era identificar se o aluno-professor sabia: transformar uma situação de erro em situação de aprendizagem; reconhecer seus enganos, sem medo de, com isso, perder a autoridade; privilegiar a lógica do sistema de numeração decimal ao invés da memorização da escrita do número; selecionar os procedimentos didáticos que melhor se coadunam com a aprendizagem de seus alunos; valorizar, na avaliação, mais o processo de aprendizagem do que 
seu produto; articular, com pertinência, a dificuldade dos problemas de Matemática com o desenvolvimento previsto para as faixas etárias de cada série; considerar que, quando a tarefa requer atividade por parte dos alunos, a probabilidade de construir um pensamento mais complexo é maior.

- Perfil A: refere-se aos alunos-professores capazes de criar e/ou identificar situações que levassem à otimização da aprendizagem, avaliando ainda - e de forma efetiva - diferentes dimensões da experiência escolar. Aqui seriam incluídos todos os participantes que escolhessem, na maioria das simulações, alternativas de práticas docentes ou justificativas teóricas condizentes com o proposto no programa, tal como:

professor considera, na avaliação, tanto o processo de aprendizagem investigando a atitude e a postura dos alunos, como a apropriação dos conteúdos trabalhados.

- Perfil B: englobava aqueles que selecionaram, nas simulações, situações propícias à otimização da aprendizagem, reconhecendo formas efetivas de avaliar diferentes dimensões da experiência escolar, sem conseguir, no entanto, implementar esses conhecimentos em sua prática pedagógica. Fariam parte desse perfil os alunosprofessores que apenas reconheciam o que era deles esperado em termos de ensino, aprendizagem e avaliação, sinalizando que a transposição da teoria para a prática era ainda uma tarefa difícil. Típico desse grupo é a resposta:

professor leva em conta, na avaliação, a apropriação dos conteúdos trabalhados, dando, no entanto, excessiva ênfase à auto-avaliação dos alunos em detrimento das observações que teceu acerca do processo de aprendizagem em sua sala de aula.

- Perfil C: abrangeria os alunos-professores que: perdessem, em sua prática pedagógica, oportunidades de criar situações que favorecessem a aprendizagem dos alunos em sala de aula, notadamente no que dizia respeito ao uso da avaliação; apresentassem respostas inconsistentes, cuja lógica não podia ser apreendida. Ilustram essa situação os exemplos: 
O professor considera tão somente a nota da avaliação, desconsiderando a participação do aluno em sala de aula;

O professor adota, na avaliação de seus alunos, critérios incoerentes, que impossibilitam compreender o que orienta sua conduta (resposta inconsistente).

\section{RESULTADOS}

Para verificar se houve modificação na postura docente, optou-se por um modelo em que se comparavam as respostas dadas pelos alunos-professores às simulações em dois momentos do programa: no início e no final. A tabela I mostra o percentual de professores que, nas diferentes posturas, foram classificados nos perfis $A, B$ e C. Diferenças de vulto entre participantes vinculados às duas universidades não foram encontradas.

Foi possível observar, nos resultados encontrados que, na avaliação inicial, o perfil A concentrou, nas três posturas, um percentual semelhante de alunos-professores, indicando que cerca de $25 \%$ deles demonstrava, já na entrada do programa, as posturas esperadas. Em relação ao perfil B, ele foi, nas três posturas, aquele em que concentraram os maiores percentuais de alunos-professores, indicando a presença de um grupo grande de participantes que dominavam apenas parcialmente a proposta do programa e os procedimentos didáticos dela decorrentes. Particularmente nesse caso, a postura II apresentou um percentual maior de participantes $(57,95 \%)$ no perfil B, intermediário, do que as demais. Finalmente, localizou-se, no perfil $C$ da postura III, 36,85\% de alunos-professores que não conheciam, nem dominavam a proposta do progra-

TABELA I

DISTRIBUIÇÃO DOS ALUNOS-PROFESSORES NA AVALIAÇÃO INICIAL POR POSTURA E PERFIL ( $N=1.272$ PARTICIPANTES)

\begin{tabular}{cccc}
\hline Perfis & \multicolumn{3}{c}{ Posturas } \\
\cline { 2 - 4 } & I & II & III \\
\hline A & $27,62 \%$ & $27,98 \%$ & $20,12 \%$ \\
B & $47,60 \%$ & $57,95 \%$ & $43,03 \%$ \\
C & $24,78 \%$ & $14,07 \%$ & $36,85 \%$ \\
\hline Total & $100 \%$ & $100 \%$ & $100 \%$ \\
\hline
\end{tabular}


ma e, portanto, não faziam uso da teoria para orientar a prática docente nos processos de ensinar, aprender e avaliar. Isso levou à conclusão de que é mais difícil coadunar formas de pensar, sentir e agir quando se trata de articular teoria e prática. Essa era a situação encontrada no início do programa

\section{Resultados da avaliação final}

pós-teste buscou responder a duas questões: se houve modificações nas posturas docentes encontradas na avaliação inicial e, em caso afirmativo, se elas ocorreram conforme as expectativas do programa; e se as diferenças surgidas entre a avaliação inicial e final eram estatisticamente significantes. Só foram consideradas válidas as respostas dos alunos-participantes que preencheram todas as questões da avaliação inicial e final $(\mathrm{N}=1$.272). Em relação à primeira questão, a análise dos resultados obtidos na segunda avaliação mostrou uma distribuição distinta da avaliação inicial, observando-se pequenas mudanças, todas na direção esperada. No entanto, só a variação de percentuais não permitia afirmar com segurança quantos e quais alunos-professores tinham, efetivamente, modificado sua postura. Para obter respostas mais precisas, fez-se necessário adotar um novo procedimento, que possibilitasse acompanhar as respostas de cada participante e explicar a variação dos percentuais em cada perfil.

Foi nesse caso construída uma variável chamada "percurso", alocandose, para cada indivíduo, um código composto por dois dígitos, em cada uma das três posturas. $\bigcirc$ primeiro deles indicava o perfil em que o indivíduo se situou na avaliação inicial e o segundo referia-se ao perfil alcançado na final, por esse mesmo sujeito. Assim, o perfil $C$ recebeu o código I, o perfil B o código 2 e o A, o código 3. Por exemplo, se em relação à postura I, o participante incluiu-se na avaliação inicial no perfil C e na final no perfil A, seu percurso, nessa postura, recebia dois dígitos: 13. Era possível, desse modo, identificar aqueles que se mantiveram em uma mesma posição de uma avaliação para a outra (códigos II, 22 e 33), bem como os que modificaram sua posição, encaminhando-se na direção esperada pelo programa (códigos 12, 23 ou 13). Foram localizados, também, os indivíduos que avaliados, inicialmente, em um determinado perfil e, na avaliação final, em um outro, considerado mais distante das expectativas do programa (códigos 2 I, 3 I e 32). Esses resultados aparecem sintetizados na tabela 2 , apresentada a seguir: 
TABELA 2

DISTRIBUIÇÃO DOS ALUNOS EM TERMOS DO PERCURSO

ENTRE A AVALIAÇÃO INICIAL E FINAL (POSTURAS I, II E III)

\begin{tabular}{|c|c|c|c|}
\hline Percurso & Postura I & Postura II & Postura III \\
\hline \multirow[t]{2}{*}{ II } & 60 & 54 & 167 \\
\hline & $05 \%$ & $04 \%$ & $13 \%$ \\
\hline \multirow[t]{2}{*}{22} & 350 & 430 & 349 \\
\hline & $28 \%$ & $34 \%$ & $27 \%$ \\
\hline \multirow[t]{2}{*}{33} & 179 & 173 & 126 \\
\hline & $14 \%$ & $14 \%$ & $10 \%$ \\
\hline \multirow[t]{2}{*}{ Total sem modificação de postura } & 589 & 657 & 642 \\
\hline & $46 \%$ & $52 \%$ & $50 \%$ \\
\hline \multirow[t]{2}{*}{12} & 163 & 102 & 143 \\
\hline & $13 \%$ & $8 \%$ & $1 / \%$ \\
\hline \multirow[t]{2}{*}{13} & 64 & 26 & 107 \\
\hline & $05 \%$ & $02 \%$ & $08 \%$ \\
\hline \multirow[t]{2}{*}{23} & 189 & 208 & 135 \\
\hline & $15 \%$ & $16 \%$ & $1 / \%$ \\
\hline \multirow{2}{*}{$\begin{array}{l}\text { Total com modificação de postura } \\
\text { na direção esperada }\end{array}$} & $4 / 6$ & 336 & 385 \\
\hline & $33 \%$ & $26 \%$ & $30 \%$ \\
\hline \multirow[t]{2}{*}{21} & 87 & 65 & 116 \\
\hline & $07 \%$ & $05 \%$ & $09 \%$ \\
\hline \multirow[t]{2}{*}{32} & 144 & 192 & 96 \\
\hline & $11 \%$ & $15 \%$ & $8 \%$ \\
\hline \multirow[t]{2}{*}{31} & 36 & 22 & 33 \\
\hline & $3 \%$ & $2 \%$ & $3 \%$ \\
\hline \multirow{2}{*}{$\begin{array}{l}\text { Total com modificação de postura } \\
\text { na direção contrária à esperada }\end{array}$} & 267 & 279 & 245 \\
\hline & $21 \%$ & $22 \%$ & $19 \%$ \\
\hline Total & 1.272 & 1.272 & 1.272 \\
\hline
\end{tabular}

Como pode ser visto, o percentual de alunos que não mostrou nenhuma alteração de perfil do pré para o pós-teste nas posturas I, II e III foi grande: respectivamente $46 \%$, 52\% e 50\%. Desses, no entanto, alguns já apresentavam, desde o início do Programa, o perfil considerado como mais adequado: 
| 4\% na postura I; |4\% na postura || e 10\% na postura III. Esses dados tendem a confirmar o fato, apontado anteriormente, de que mudanças de postura são difíceis de serem obtidas em curto prazo.

Em relação aos percentuais de alunos-professores que alteraram seus perfis para outros mais próximos dos desejados, eles foram, nas três posturas, respectivamente $33 \%, 26 \%$ e $30 \%$. Isso pode ser considerado positivo, em especial quando comparados com os percentuais daqueles que mudaram seu perfil de um mais próximo do esperado na avaliação inicial para outro mais distante na final: $21 \%$, 22\% e 19\%, nas posturas em estudo.

Aplicou-se, então, sobre tais resultados, o teste de quiquadrado, com o objetivo de verificar se os perfis haviam se mantido (ou não) de um momento para o outro. Os resultados confirmaram, do ponto de vista estatístico, que, nas três posturas, houve mudanças na distribuição relativa à segunda avaliação, com aumento no percentual de respostas nos perfis considerados mais complexos e, portanto, tidos como mais desejáveis. Esses resultados foram interpretados como indicativos de que o programa teve um impacto positivo no desempenho dos participantes ${ }^{4}$.

Para investigar melhor esse resultado, adotou-se um outro procedimento: criou-se uma variável "pontuação", por meio da qual era possível sintetizar a realização dos participantes no conjunto das três posturas, permitindo, dessa maneira, que comparações de interesse fossem feitas. Essa variável pontuava cada aluno-professor no intervalo de três a nove pontos: o menor valor correspondia aos que foram classificados como perfil $C$ nas três posturas (I, II e III) avaliadas. Já o maior (nove) indicava o aluno-professor classificado como perfil A em todas elas. O gráfico I mostra as diferenças encontradas entre as duas avaliações, por meio da variável "pontuação".

Como se pode observar, a distribuição dos alunos-professores na variável "pontuação" encontrava-se, na avaliação inicial, mais à esquerda, implicando maior freqüência em valores mais baixos, ou seja, posturas que mais se distanciavam do esperado pelo PEC-Municípios. Na avaliação final, foi possível verificar que houve um deslocamento dessa distribuição para a direita, sinali-

4. Os valores do quiquadrado, os graus de liberdade e a significância assintótica foram, segundo as posturas, os seguintes: postura I: 67,08; graus de liberdade 4, sig. assintótica 0,000; postura II: I|3, 56, graus de liberdade 4, sig. assintótica 0,000; postura III: |43, I8, graus de liberdade 4, sig. assintótica 0,000. 
GRÁFICO I

DISTRIBUIÇÃO DOS RESPONDENTES, SEGUNDO A VARIÁVEL RESUMO NAS TRÊS POSTURAS, NA AVALIAÇÃO INICIAL E FINAL

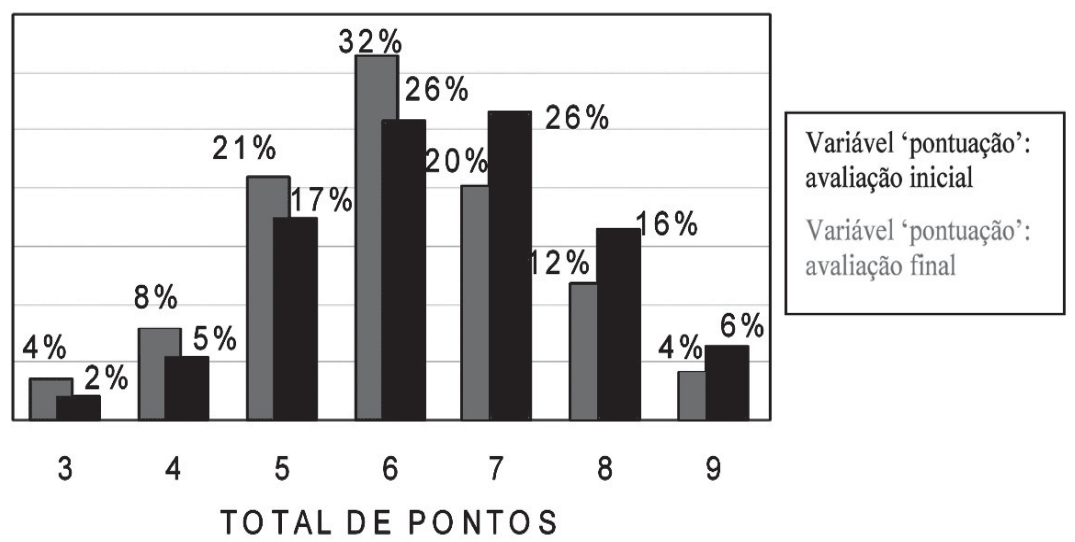

zando maior freqüência em valores mais elevados, ou seja, posturas em maior concordância com o que era nele apregoado.

Mas será que a descrição feita dos resultados observados no gráfico । era estatisticamente significante? Procurou-se, assim, saber qual era a correlação entre a variável "pontuação" do pré e do pós-teste. Foi aplicada, para tanto, a técnica de regressão linear simples, tendo como variável independente os valores obtidos na avaliação inicial e, como dependente, aqueles alcançados na avaliação final. Essa técnica foi empregada em dois conjuntos de dados: os que diziam respeito aos participantes vinculados à Universidade I e, em seguida, aos ligados à Universidade 2 . Os resultados indicaram que, para ambas as universidades, a correlação foi negativa e estatisticamente significante ${ }^{5}$. Concluiu-se, assim, que os alunos-professores ligados a cada uma delas tiveram seus resultados iniciais associados inversamente às modificações de posturas: quanto mais baixo era o valor da variável "pontuação" na avaliação inicial, maior ele o era na final. Isso equivale a dizer que quanto mais precário fosse, no início do

5. Em ambos os casos, as correlações obtidas foram negativas e bastante próximas, a saber: Universidade I: 0,58 $[\{\mathrm{F}(1 ; 930)=46 \mathrm{I}, 8 ;$ sig. $=0,000\}]$; Universidade $2:-0,54[\{\mathrm{~F}(1 ; 338)$ $=$ I44,2; sig. $=0,000\}$. 
programa, o domínio dos aspectos investigados em cada postura, maior a tendência para, em seu final, modificá-los no sentido esperado.

\section{CONSIDERAÇÕ ES FIN AIS}

Cabe retomar aqui alguns dos resultados alcançados. $\bigcirc$ primeiro deles diz respeito ao fato de que cerca de $30 \%$ dos participantes sofreram alterações de perfil, e no sentido esperado, nas três posturas. Isso significa que o programa propiciou muitas e variadas informações e experiências (discussões, exercícios, tarefas etc.), sempre em um ambiente acolhedor e instigante ${ }^{6}$, de modo que esses alunos-professores apresentaram, ao final do programa, maior tendência para: dominar e planejar situações didáticas que envolviam os conteúdos básicos das áreas de conhecimento (postura I); reconhecer e empregar adequadamente os recursos e tecnologias disponíveis no processo de ensino-aprendizagem (postura II); valer-se da teoria para orientar a prática docente e a avaliação (postura III).

Esse resultado foi, inegavelmente, além das melhores expectativas, porque mudar as formas de pensar, de sentir e de agir parece não ser nem simples nem fácil. Quando se fala de mudanças, há que se ter em mente, portanto, que elas ocorrem por meio de um processo complexo e moroso. De um lado, ele implica perdas: deixar de ser algo para ser uma outra coisa é se colocar em situações de risco, uma vez que, eventualmente, não se sabe ainda como lidar com elas. De outro, requer investimento cognitivo e emocional de vulto que, por isso mesmo, faz surgir resistências fortes, que explicam a permanência, em um mesmo perfil, de cerca de $40 \%$ dos alunos-professores.

Tudo isso permite aquilatar bem as vicissitudes da mudança, em especial quando elas são esperadas em curto prazo. Elas podem explicar, por exemplo, a razão pela qual cerca de $20 \%$ dos participantes passaram, ao longo do programa, de uma postura mais próxima da almejada para outra, mais distante da pretendida. Tudo leva a crer que o processo de mudança segue um percurso conturbado, marcado por desestabilizações nas formas de ser, pensar e agir. Nessas circunstâncias, as posturas passam por um período de instabilidade, em

6. Consultar, para maiores detalhes, relatórios técnicos da Avaliação Externa do PEC-Formação Universitária/Fundação Carlos Chagas, 2002. 
que ora predominam alguns de seus aspectos, ora outros. $\bigcirc$ programa parece ter ocasionado, para esses participantes, inconsistências entre os modos de pensar, sentir e agir, levando as posturas iniciais a fragmentarem-se, sem tempo suficiente para se recompor até o término do PEC-Municípios.

Por último, vale ressaltar que, na postura II, o percentual de alunos-professores que conseguiu atingir o perfil A (tido como mais adequado) saindo do perfil $B$ (intermediário) foi o dobro daquele encontrado quando se saia do perfil $\mathrm{C}$ e atingia-se o $\mathrm{B}$. Esse dado pode ser uma pista importante, a ser mais bem investigada: alterações de posturas parecem ser mais freqüente entre participantes que iniciam um determinado programa de capacitação docente em um patamar intermediário, anterior ao que se almeja conquistar. Fica claro, portanto, que um diagnóstico do perfil de entrada dos alunos-professores em termos de posturas a serem alcançadas pode ser importante não só para avaliar a eficácia de programas de capacitação docente, como, também, para orientar seu delineamento.

\section{REFERÊN CIAS BIBLIO GRÁFICAS}

ATHERTON, J. S. Resistance to learning: a discussion based on participants in in-service professional training programmes. Journal of Vocational Education and Training, v.5I, n. I, p.77-90, 1999.

COLL, C. et al. Os Conteúdos na reforma: ensino e aprendizagem de conceitos, procedimentos e atitudes. Rio Grande do Sul: Artmed, 1992.

EISER, J. R. Psicologia social. Madrid: Pirámide, 1989.

MISLEVY, R. J. Evidence and inference in educational assessment. Educational Testing Service, 1996. (CSE Technical Report 414. Robert J. Mislevy). Disponível em: www.cse.ucla.edu/ Reports/TECH4I4.PDF. Acesso em: 21.7.2006.

NUNES, C. A. A.; NUNES, M. M. R.; DAVIS, C. Assessing the inaccessible: metacognition and attitudes. Assessment In Education: principles policy and practice. Bristol (UK), v. I0, n.3, p.375-388, nov. 2003.

Recebido em: setembro 2006

Aprovado para publicação em: novembro 2006 